\title{
Perinatal care experiences of immigrant Syrian women: a qualitative phenomenological study
}

Burcu Vurgec, ${ }^{1}$ Sule Surucu, ${ }^{1}$ Cemile Köroglu ${ }^{2}$ and Hibe Ezzo ${ }^{1}$

'Department of Midwifery, Faculty of Health Sciences, Cukurova University Adana, Turkey (Correspondence to: Burcu Vurgec: burcuavcibay@hotmail. com). Cemile ONAT KÖROGLU, MSc, Lecturer ${ }^{2}$ Department of Nursing, Faculty of Health Sciences, Hatay Mustafa Kemal University, Antakya, Hatay, Turkey.

\begin{abstract}
Background: Adverse birth outcomes of immigrant women and neonates are associated with the quality of perinatal care. For this reason, examining immigrant women's experiences of perinatal care is necessary if host country care systems are to respond appropriately to migration.
\end{abstract}

Aims: The aim of the study was to evaluate the perinatal care experiences of immigrant women.

Methods: The qualitative phenomenological design used in the study enabled to make an in-depth exploration of immigrant women's experiences. The participants were 24 women who had a pregnancy within the past 6 months and lived in Adana, Turkey, between September and December 2019. Data were collected using a semi-structured form through the snowball method. Qualitative data were analysed using the thematic analysis method.

Results: The participants' mean age was 21.41 [standard deviation (SD) 3.86] years. Mean age at first pregnancy was 17.27 (SD 4.59) years. It was determined that immigrant women received insufficient maternity services. In thematic analysis, 4 main themes indicating barriers to sufficient perinatal care were identified. The barriers to maternal care services were: language barrier, cultural incompatibility, decreased social support and inadequate information.

Conclusion: Our findings indicated that perinatal care for immigrant women was inadequate and their experiences were generally negative. Although the barriers seem separate, they are actually intertwined, with the language barrier appearing to be the main one. Innovative approaches are needed to solve this problem. Mobile applications that translate instantly can be used by both immigrant women and health care professionals.

Keywords: immigrants, refugees, maternal health, pregnancy, perinatal care

Citation: Vurgec B; Surucu S; Köroglu C; Ezzo H. Perinatal care experiences of immigrant Syrian women: a qualitative phenomenological study. East Mediterr Health J. 2021;27(12):1173-1181. https://doi.org/10.26719/emhj.21.065

Received: 30/12/20; accepted: 15/06/21

Copyright (c) World Health Organization (WHO) 2021. Open Access. Some rights reserved. This work is available under the CC BY-NC-SA 3.0 IGO license (https://creativecommons.org/licenses/by-nc-sa/3.o/igo).

\section{Introduction}

For many women, the transition to motherhood is the most important developmental life event. Perinatal care includes the maternal care provided in the antenatal care, birth, and postnatal care facilities. Care and social support, starting with pregnancy, is the key to safe birth and maternal and child health (1). This process, especially when it happens simultaneously with immigration requiring a new adaptation, may negatively affect the woman's health and well-being $(1,2,3)$. Immigration can result in negative outcomes on people's well-being and physical and mental health. While many immigrant women experience healthy pregnancies, issues about establishing a new life could affect the pregnancy process negatively and cause women to experience poorer perinatal outcomes than expected $(1,4)$.

Studies on immigrant women show that they have increased risks in terms of pregnancy- and birthrelated complications such as anaemia, bleeding, fetal distress, stillbirth and preterm birth (3,5). More negative physiological and psychological maternal consequences are reported in immigrant women in comparison to the local population. A sample in Canada showed that prevalence of postpartum depression was 5 times greater in Syrian immigrant mothers compared with the local population $(6,7)$. It has been reported that this ratio could be higher in developing countries (8).

These negative results suggest that it is necessary to eliminate the barriers to high quality perinatal care (9). Perinatal care experiences of immigrant women and those of local women demonstrate significant differences. Immigrants are more at risk in terms of negative pregnancy and birth outcomes (10). Current data on the migrant sample can be accessed from the 2018 Turkey Demographic and Health Survey Syrian Migrant Sample results in Turkey (11). From this survey: the average number of children among the Syrian women is 5.1 ; it is 2.3 in the local population; the adolescent birth rate is $39.3 \%$ in the Syrian sample, and $3.5 \%$ in the local population; and the proportion having 4 or more prenatal check-ups is $46 \%$ among Syrian women while it is $90 \%$ in the local population. No data have been published regarding the maternal mortality ratio among Syrian women, however, the higher infant mortality rate has been emphasized: the rate is 22 per thousand live births in the Syrian sample (11) but 6.7 per thousand in the 
local population (12). While low birth weight is $20 \%$ in the Syrian sample, it is $12 \%$ in the Turkish sample. The proportion of those who never received postpartum care is 2 times greater than the Turkish sample (10\%). Comparative studies on birth outcomes in Turkey report higher rates of anaemia and higher rates of pre-term birth and neonates with low birth weight among Syrian women in comparison to the local population (13-17).

The quality of perinatal care may be affected by many factors. In addition to the cultural background, maternal and fetal health could be affected by factors such as women's previous experiences, immigration conditions, beliefs, education level, financial status in the host country, social networks, access to services, and communication in the services accessed (18-21).

In the 10th year of forced migration from Syria, Turkey hosts the highest number of immigrants (22), and Adana is the city with the 5th highest Syrian population $(11.2 \%)$ (23). However, no studies have investigated the perinatal care of immigrant women. Hence, the purpose of this study is to evaluate Syrian immigrant women's experiences of perinatal care in Adana in line with maternal-fetal care standards and identify the barriers to receiving adequate care.

\section{Methods}

\section{Design and sample size}

This study utilized a phenomenological qualitative design based on immigrant women's perinatal care experiences. The research design was structured according to Giorgi's phenomenological research approach. According to Giorgi, phenomenological studies aim to understand individuals' world views and experiences that are meaningful for people sharing these experiences $(24,25)$. The main purpose of phenomenology is to reduce the individual experiences regarding a phenomenon into a universal explanation (26). Phenomenological studies in immigrant research are reported to be effective tools in the development of policy interventions (27). The phenomenon of the study is perinatal care, and the main research questions are:

- How do Syrian immigrant women experience the care in the pregnancy, birth, and postpartum processes?

- What are the barriers to Syrian immigrant women receiving qualified perinatal care?

\section{Data collection}

The study was conducted with immigrant women living in the Yüreğir province of Adana, Turkey, between September and December 2019; the region where the study was conducted includes high numbers of Syrian immigrants and asylum seekers. The study, which aimed to evaluate the perinatal care experiences, included Syrian immigrant women who lived in Adana and experienced a pregnancy within the past 6 months. According to Creswell and Poth, the participants could comprise 5-25 indi- viduals who have experience regarding the phenomenon under investigation (25); however, the number of participants could be considered sufficient when the concepts and processes elicited start to repeat. Data transcribed after each interview were determined to have data saturation, and the study was completed with 24 women.

All the participants lived in their own houses in the city centre. The interviews were administered in their homes because more reliable data were considered to be elicited in a place where the participants felt more comfortable. The starting person of the study was the daughter of an opinion leader; she taught how to read Quran to Syrian women. She was a religious leader trusted by both women and their families, and they consulted her on various topics. As the research population had a conservative family structure and was vulnerable, purposeful sampling was utilized to choose this starting person to increase the reliability of the research and researchers. This communication network was utilized for the successive interviews. The participants were contacted before the interviews; they were introduced to the researcher and informed about the duration of the interviews and expectations about the environmental conditions during the interviews. The participants were visited on days and times determined by them. During the visits, the participants were given little gifts specific to the host country. The interviews were conducted using a semi-structured form and started after informed consent was received from the participants. All the interviews started with descriptive questions about demographics and perinatal care and continued with semi-structured questions. The in-depth interviews were conducted faceto-face and continued by moving from semi-structured questions to exploratory questions.

The first question asked during the interviews was: "Could you please share the pregnancy, birth, and postpartum experiences of Syrian immigrant mothers with us?" Other main questions were: "Did you experience any difficulties in accessing the maternal care you needed in the pregnancy period. If you experienced any difficulties, could you please tell us about them?", "Did you experience any difficulties in accessing the care you needed during labour? If you experienced any difficulties, could you please tell us about them?", "Did you experience any difficulties in accessing the maternal care you needed in the postpartum period? If you experienced any difficulties, could you please tell us about them?", "Can you tell us about the process of transition to motherhood as a Syrian immigrant woman? How was living in a foreign country like?"

Then there followed the sub-questions: "How did experiencing your pregnancy in a foreign country make you feel?", "Could you please tell us about how it was like to experience labour in a foreign country?", "Could you please describe the feelings of living an adaptation process in the postpartum period in a foreign country?", "What are your suggestions about a better motherhood experience as an immigrant woman?". The interviews took around 45-90 minutes. 
One of the authors (HE), who took the assistant researcher role in this study, is a Syrian immigrant student who is proficient in Turkish and Arabic and is enrolled in 3 rd year in the midwifery department. The use of the mother language is important while expressing emotions. All of the interviews were conducted in Arabic and HE did simultaneous interpreting during the interviews. Two authors (BAV and COK) did the recordings in Turkish. Crosschecks were done during the interviews. After each interview, the notes taken by the researchers were reviewed quickly, and any missing or inadequate parts were completed.

\section{Data analysis}

Raw data obtained from the interviews were analysed manually using the procedures recommended by Giorgi. The analysis methodology includes 5 steps: transcribing and familiarizing (reading or listening several times); identifying meaning units; re-grouping meaning units in clusters; transforming the meaning units into descriptive expressions; and synthesis and integration (24).

The recordings were transcribed on the same day after the interviews. Arabic interviews were compared with Turkish recordings. One week later, data were evaluated again to eliminate the probability of being affected by the emotional intensity of the interviews and to protect data objectivity and prevent data loss. In the first step of the analysis, all the transcriptions were read several times to gain an idea about the participants' experiences. This step was performed without any analysis purposes in mind. In the next step, the transcriptions were read for a second time to determine the meaning units. The meaning units were formed by reading and rereading, counting words, and checking alternatives with the same meanings. The next step included the transformation of the data into smaller and more manageable meaning units, and important expressions regarding the phenomenon under investigation were defined. Main themes and sub-themes representing the experiences regarding the phenomenon were determined. All the converted themes were synthesized into a consistent and explanatory statement of all participants' perinatal care experiences.

\section{Rigour of study}

Theresearchersfollowedsomestandardstoincreasetherigour andvalidityofthestudy.First,cross-checksweredoneduring theinterviews, and thetranscriptions of therecordingswere madebytheresearcherswhoconducted theinterviews.Next, dataanalysiswasperformedbymidwifeacademicswhoare experienced in both perinatal care and qualitative analysis (BAV,SGS;SGSwasnotpresentduringtheinterviews, which enhancedverificationindataanalysis).Thentheresearchteam workingonthethematicanalysis(BAV,SGS) usedinter-coder reliability,andtherebyaugmentedthereliabilityofthedatain reading,codingandanalysis.Oncethefirstcodesweredefined, theywerecombinedandrefinedtodeterminethethemes.The themeswerethencomparedwitheachother,thefindingswere discussed, and the main themes were identified.

\section{Ethical considerations}

Theinstitutionalreviewboardof theparticipatinguniversity (No:89/14062019-83)providedethicalapprovalforthisstudy. Studypermission was obtained from the Directorate of MigrationPolicyandProjects(No:62103649-00o-E.46812).Theinformedconsentpartofthestudyprovidedtheparticipantswith thevolunteerandanonymousnatureof thestudy thatwould allow withdrawal at any time they wanted.

\section{Results}

\section{Participants}

Among the24participants, meanagewas21.41[standarddeviation(SD)3.86] years. Theaverageageatthefirstpregnancywas17.27(SD 4.59)years, and the averagenumberof pregnancieswas3.08(SD1.89).Nineteenparticipantshadlessthan 4prenatalcheck-ups. Thethematicanalysisrevealed 4main themesthatwereconsidered toaffect thequalityand nature ofthewomen'sprenatalcareexperiences:thelanguagebarrier,culturalincompatibility, inadequateinformationanddecreased social support (Table 1).

\section{Language barrier}

None of the participants was proficient in Turkish. Not using the same language or lack of interpreting support was a common problem mentioned. One participant,

\begin{tabular}{ll}
\hline Table 1 Barriers to perinatal care access among immigrant pregnant women, Adana, Turkey, September-December 2019 \\
Main theme & Subthemes \\
\hline Language barrier & Difficulties in accessing health care \\
& Difficulties in using health care effectively \\
& Difficulties in articulating health problems \\
& Differences in beliefs and attitudes with the host country \\
& Disrespectful and negative attitudes of health care providers \\
Tultural incompatibility & Trying to adapt to a new culture as a woman \\
& Feeling of insecurity \\
& Inadequate, incomplete and limited perinatal care \\
& Inadequate awareness \\
Inadequate information & Inadequate compliance policies \\
& Decreased social support \\
& Support from family, relatives and friends \\
Decreased social support & Feelings of loneliness, isolation, and longing \\
\hline
\end{tabular}


who was in her third pregnancy, declared the dissatisfaction caused by the language barrier as:

“... I was coughing. My husband spoke a little Turkish. He was trying to explain that I was feeling nauseous and coughing. They were just telling me to get an appointment and get examined. They did not listen to us; I got examined. The doctor just told me to have some tests. Tests, tests ... My husband was trying to explain. The doctor insisted that first, we needed to have the tests." (Participant 1).

Another participant stated her experience with the language barrier as: “... It was not like this when I was pregnant in Syria. The doctor would tell me everything during the ultrasound examination. We spoke the same language. Here as if everything is numbers ... checking blood tests, prescribing, and saying good, good ..." (Participant 5).

The participants who needed the presence or guidance of a person during labour were found to have difficulties. The women who were generally accepted to the delivery room alone combined the loneliness with the feeling of helplessness due to the language barrier.

"I did not know what to do when my birth pain started. The midwife came and looked at me, wrapped something on my abdomen. Then she said a word in Arabic (pain). I thought she spoke Arabic and started to explain (laughing). Then she started to speak in Turkish. I learned that she knew only one word in Arabic. Now I am laughing, but at that moment I did not know what to do. I said 'God, what am I going to do? They do not understand me, how will I get rid of this pain?" (Participant 10).

The language barrier was a problem in both pregnancy care and social life.

"We are surprised to hear someone speaking Arabic when we go outside. Turkish people are surprised to hear us speaking Arabic. You are trying to communicate with them, but it does not happen. I mean, it is difficult." (Participant 11)

The number of interpreters is not adequate in the hospital. Therefore, interpreters are usually positioned in polyclinics, hospitalization procedures, and emergency services. An excerpt is as follows:

"I expected the doctor to visit me after surgery. The doctor was a man while I was going to surgery, and the one who visited was a woman. We do not have an interpreter whenever we need it, so we bring someone else for help. Sometimes we ask someone to interpret on the phone, but not everyone accepts this..." (Participant 13)

\section{Cultural incompatibility}

The participants focused largely on their beliefs and the number of births associated with their cultural values. They stated that they received verbal or nonverbal reactions from social environments particularly on these issues. They sometimes experienced these disrespectful reactions while they were receiving care.

"When I went to the hospital, I asked for a female doctor. Then I saw that there were so many people waiting there, so I asked the interpreter if it was possible to change her and find another doctor. He told this to the secretary. The secretary told something angrily; I guess she was saying what makes the difference if it is male or female. Then the interpreter said there was no other option. I had to wait for my turn. My husband does not let me see a male doctor." (Participant 7).

"While we are walking on the street, they look at our black chadors and say something ... I do not understand what they are saying, but I know that they are talking about this. They sometimes shout and say 'here is Turkey, not Syria'. But this is my belief, and this is what we are. There are also Turkish women like this. Are they doing the same thing to them?... Mostlywomen are doing it. I feel very sad about it." (Participant 22)

The participants stated that the number of children was part of their culture. Some participants thought that they received reactions about this and found it offensive.

"They asked me how many children I had in the hospital, I showed 5 with my hand. They said 'enough ... enough ...' Why enough? Children are good. (Participant 17)

Another participant stated that people generally saw all Syrian people the same, but she said there are differences and they should not be considered the same.

"They think that all Syrian people are the same and have children one after another. I am not like this. They think we all have many children. I do not get pregnant before 3 years." (Participant 2).

\section{Inadequate information}

Most of the participants experienced difficulties in communicating with their relatives during the labour process; they were not informed about the implementations during pregnancy; and most of the time they did not understand the things told to them. Follow-ups are important even for women who have experienced pregnancy before. One participant told us:

"In my 2 previous pregnancies in Syria, the doctor told me to use folic acid and I did. However, here they did not tell me such thing and I did not use it." (Participant 8)

Health care providers had the necessary Arabic language information forms. Education level is low among Syrian women, and some of them cannot even read in their own language. One participant stated her ideas regarding this issue:

"A nurse came to our room after labour and checked if I was bleeding. Then she gave me a piece of paper with pictures and texts on it. I could not read the paper. Other women in the room were Turkish. She gave the same paper to them and then she started to explain. She was showing something; I watched. The nurse was turning and showing me as well. If you ask, she told so many things, but I only know the things she showed." (Participant 4)

A participant who stated that she wanted to attend antenatal classes expressed her feelings:

"While waiting for the test results, we were sitting opposite the antenatal course classroom in the hospital garden. We asked each other about what that place was. Then a person sitting next to us said that it was a classroom for an antenatal course. She told us that they were teaching things to decrease pain during labour. I had a lot of pain in my first birth. I also wanted to participate when I learned that it was free. But then I learned 
that it was not given in Arabic. I wish I could have learned. I might have had less pain." (Participant 2)

\section{Decreased social support}

The presence of social mechanisms is important for people, who are social beings. Some excerpts regarding decreased social support are as follows:

"I was born in one house and lived there until I got married. My daughter will not have one house because we are moving every year. My daughter will not have a mother's or grandmother's house." (Participant 6)

"When I first got pregnant, I was alone here. I was alone in Turkey as well; I did not have my family and relatives. I cried a lot and felt so sorry when I learned that I was pregnant. I wanted my family to receive the pregnancy news and become happy with me. No one knew that I was pregnant and no one saw that I had a daughter. Only one Turkish neighbour I had felt so happy. Yes, my neighbour felt happy with me. But she was not my aunt for example. I wish I had had my family with me then." (Participant 24)

"My midwife was very good. She never got angry with me. But another midwife got very angry with a woman next to me. When she left, I talked with her and we became friends. I told her not to shout and cry. She said these would not have happened if we were in Syria. I agreed, but I said we had no choice but to get used to this country. She then calmed down, she called me sister when she needed something. When we were in Syria, we had a birth at home and we had our mother or sisters with us." (Participant 6)

Immigrant women, who have to deal with many difficulties due to forced migration, cannot meet these needs in the postpartum period adequately. One participant who missed her mother's support explained her feelings:

"Loneliness is so hard. I do not have my mother and family here. I wanted to be with my mother. I am so sad about it. This is my fourth child. If I had my mother with me, she would take care of other children as well. She would help me. I sometimes need help even with cooking. If I had my mother here, she would help me. My husband also helps, but it is not like my mother's help." (Participant 9)

\section{Discussion}

The results show that Syrian immigrants have negative experiences with maternal care services, and there are barriers in accessing these services. Language barrier, cultural incompatibility, reduced social support and insufficient information prevent immigrant women from receiving maternal care services at an optimum level. Research conducted so far suggests that maternal care services and access to services are still insufficient for refugee women forcefully displaced in humanitarian crisis situations. This insufficiency stands as a barrier to full enjoyment of maternity care for refugee women. Pregnancy is an important and special experience in a woman's life. This process can sometimes be defined by complex emotions. The difficulties of being an immigrant could make it even more complicated. Although the host countries are different, the difficulties experienced by women in their motherhood are quite similar. Chu et al. defined immigrant women's first labour experiences with "experiencing a crisis", "depending on others", and "looking for solutions" themes (19). These themes were reported to be associated with barriers such as inadequate perinatal care, language barriers, social isolation, lack of knowledge, and lifestyles that depend on others. The World Health Organization reported the factors affecting the health of mothers and neonates as the development index of the mother in regard to gender, the health system of the country they come from, socioeconomic level, education level, use of mother tongue, social network, duration of access to the care and interventions in the host country, and strong integration policies $(1,4,28-30)$. The results of our study are in line with the previous research.

Communicating effectively and understanding maternal care systems are of great importance while seeking perinatal care. Consistent with previous research, our findings indicate inadequate access to interpreter services (18). For many immigrant women, the language barrier prevents accessing information about the services available to them (2-4,18,31-34). In addition, limited language skills decrease women's selfconfidence in expressing their needs and preferences (32). The "fear, anxiety, and pain" experienced in the labour process is closely associated with stress. Notably, the fear experienced while having a very special experience is associated with the consequence of being an immigrant.

The quality and nature of information in perinatal care services are important for all women. However, it is even more important for women who do not speak the local language or who do not fully understand the culture and health care system of the host country. The condition is even more serious if women come from a health system with no regular maternal services. Besides, Syrian women's education level is generally low. The health system for immigrant women is generally designed for the middle-class and targeting the host majority (33). Therefore, individuals could tend to benefit from impractical, illegal, and cheaper health care options. Women sometimes evaluate the information and education processes like an opportunity to socialize. Orgel and Merve reported high participation and satisfaction rates in the antenatal classes designed for Syrian women (99.1\%) (34). The researchers concluded that the interest was associated with the perception of seeing these courses as an opportunity to leave home, socialize with other women and communicate with medical experts in the host country.

Culture is an important element that shapes the values of a society. The cultural complexity experienced by communities that come with migration is a factor that makes life difficult. Studies conducted with Muslim immigrant women showed that women particularly emphasized the importance of continuous care and stated that they preferred midwives throughout pregnancy and female health professionals in the follow-ups after 
labour (35). Sometimes their desire to choose the sex of doctors was responded to disrespectfully and they were marginalized. They were subjected to this discrimination not only in the institutions but also in social life. They were excluded sometimes due to their language or clothes. The most dramatic effects of immigration are experienced by women and children. The host country is a safe shelter for them. One of the participants stated her feelings as follows: "We were waiting at the border. The Syrian side was completely dark. The Turkish side had lights. I said, 'God there is still a safe place in the world'. Maintaining the definition of this safe area is highly important, particularly for women.

Many studies have reported that immigrant women had difficulties in coping without their families and social networks and that they needed emotional support $(13,18,20,32)$. Family support and social support help women to become more resilient when they encounter language and cultural problems in accessing maternal services (18). In the postpartum period, Syrian women receive strong support, particularly from their relatives. The participants indicated the lack of this support. Losing this support, traditions and cultural practices in relation to labour could make immigrant women more inclined to postpartum depression (36).

This phenomenological study is a pioneer study investigating immigrant women's perinatal care experiences, and being a field study is its strength. On the other hand, the study has some intertwined strengths and limitations. While the use of a qualitative method enabled the understanding of experiences regarding a certain phenomenon better due to the participants' vulnerable history, the focus was on a limited population. Therefore, the results cannot be generalized.

Another limitation is that the legal status of the sample was not identified, and the term "immigrant" was used to describe the participants. The Turkish Republic Directorate-General for Migration Management defines Syrian people's status in Turkey as "asylum seekers". Immigration status was not asked to the participants as it might have caused some drawbacks. Therefore, the immigrant status of the participants in this study might be different, and the study might not provide explicit information for the studies on immigrant people having specific status. However, one strength of the study is that it contributes to the limited literature on the perinatal care experiences of immigrant women living in Turkey.

The last limitation is that the study represents the experiences of immigrant women living in the city centre, which may considered to be both a strength and a limitation of the study. In the camps, health services are provided regularly by Turkish and Syrian health personnel. In this situation, individuals are able to overcome various barriers in accessing health services. However, the economic or social insufficiencies of the sample living by their own means might have prevented access to health services. For this reason, the study includes bias consequential on the effects of the living conditions.

\section{Conclusion}

In conclusion, perinatal care is important to minimize adverse birth outcomes, especially in vulnerable groups, including pregnant immigrant women. Mutual trust between immigrant women and health care providers is important for providing quality care. The importance given to immigrant women, particularly by midwives, in perinatal care is an serious responsibility within the framework of cultural awareness. Immigrant health workers, as part of a strong integration system, should be employed not only in camps but also in health institutions in cities. Immigrant women's knowledge about how to navigate the health care system could decrease negative perinatal outcomes. In this regard, the elimination of the language barrier is necessary for providing equal care. Language is the most important problem for immigrants. Innovative approaches are needed to solve this problem. Mobile applications that translate instantly can be used by both immigrant women and health care professionals.

\section{Acknowledgement}

We would like to thank to all the women who are the spokespersons of their peers.

Funding: Scientific Research Projects Unit, Cukurova University (TSA-2019-12055).

Competing interests: None declared.

\section{Expériences des femmes syriennes immigrées en matière de soins périnatals : étude phénoménologique qualitative}

\section{Résumé}

Contexte : Les issues défavorables de la grossesse chez les femmes immigrées et les nouveau-nés sont corrélées à la qualité des soins périnatals. Pour cette raison, il est nécessaire d'examiner les expériences des femmes immigrées en matière de soins périnatals pour que les systèmes de soins du pays d'accueil puissent apporter une réponse appropriée aux migrations.

Objectifs : La présente étude visait à évaluer les expériences des femmes immigrées en matière de soins périnatals. 
Méthodes : Le modèle phénoménologique qualitatif utilisé pour l'étude a permis d'explorer de façon approfondie les expériences des femmes immigrées. Les participantes se composaient de 24 femmes ayant été enceintes au cours des six mois précédant l'étude et ayant vécu à Adana (Turquie) entre septembre et décembre 2019. Les données ont été collectées à l'aide d'un formulaire semi-structuré selon la méthode boule de neige. Les données qualitatives ont été analysées selon la méthode d'analyse thématique.

Résultats : L'âge moyen (écart type) des participantes était de 21,41 $(3,86)$ ans. L'âge moyen (écart type) lors de la première grossesse était de $17,27(4,59)$ ans. Il a été établi que les femmes immigrées ne bénéficiaient pas de services de maternité suffisants. Lors de l'analyse thématique, quatre thèmes principaux indiquant les obstacles à des soins périnatals suffisants ont été identifiés. Les obstacles aux services de soins maternels étaient les suivants : barrière linguistique, incompatibilité culturelle, diminution du soutien social et information inadéquate.

Conclusion : Les résultats indiquent que les femmes immigrées ont bénéficié de soins périnatals insuffisants et que leurs expériences étaient généralement négatives. Bien que les obstacles paraissent indépendants, ils sont en réalité étroitement liés. Le principal d'entre eux semble être la barrière de la langue. Des approches innovantes sont nécessaires pour résoudre ce problème. Les applications mobiles proposant des traductions instantanées peuvent ainsi être utilisées à la fois par les femmes immigrées et les professionnels de soins de santé.

$$
\text { بوارب النساء السوريات المهاجرات فيما يخص الرعاية في الفترة المحيطة بالو لادة: دراسة كيفية للظو اهر }
$$

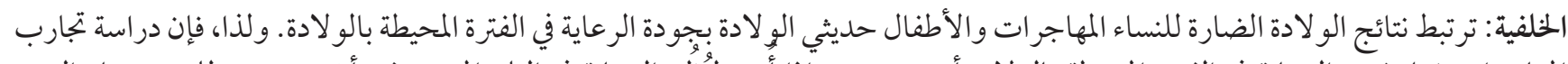

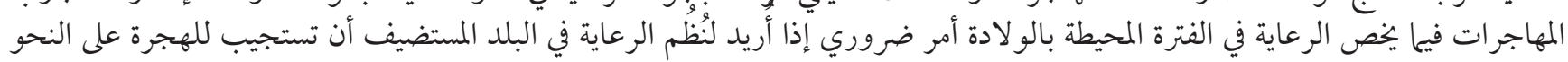
المناسب.

$$
\text { الأهداف: هدفت هذه الدراسة إلى تقييم تجارب النساء المهاجرات فيما يخص الرعاية في الفترة المحيطة بالو لادة. }
$$

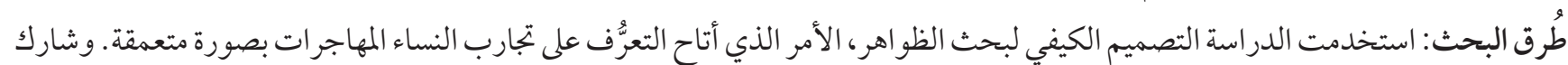

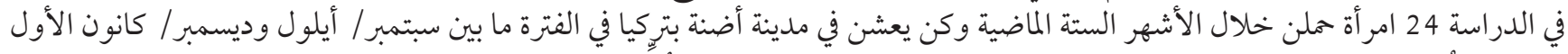

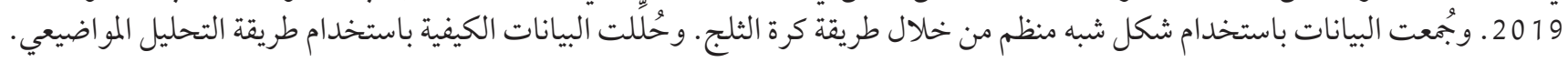

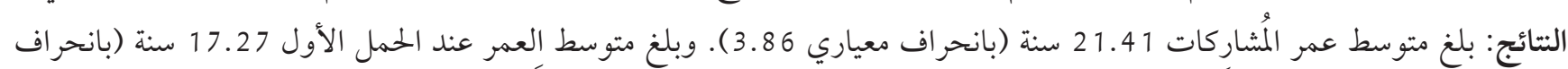

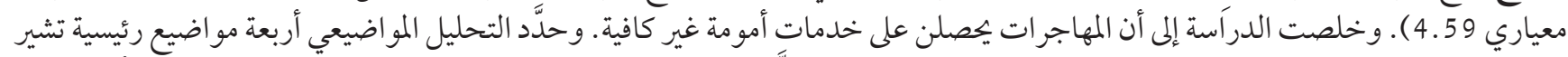

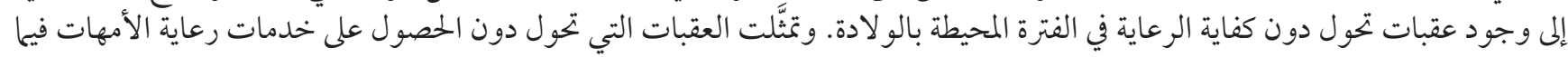

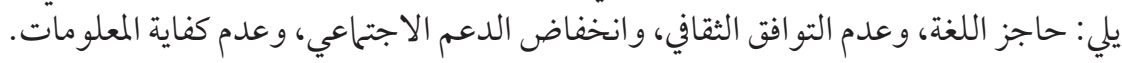

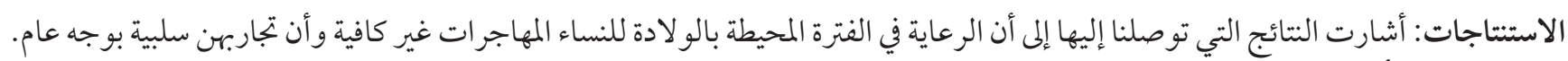

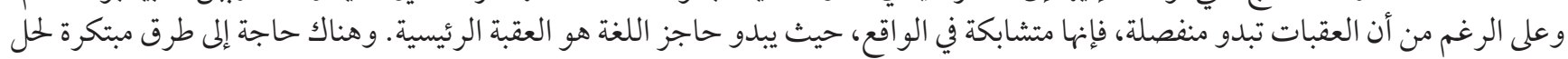

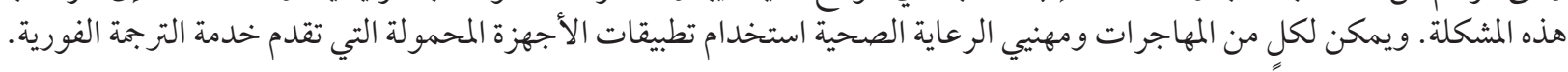

\section{References}

1. Improving the health care of pregnant refugee and migrant women and newborn children. Copenhagen; World Health Organization; 2018 (https://www.euro.who.int/_data/assets/pdf_file/0003/388362/tc-mother-eng.pdf?ua=1, accessed 15 December 2020).

2. Operational refugee and migrant maternal approach (ORAMMA) practice guide for perinatal care of migrant, asylum- seeking \& refugee women. ORAMMA; 2017 (http://oramma.eu/wp-content/uploads/2018/12/ORAMMA-D4.1-Practice-Guide_REVIEWED. pdf, accessed 15 December 2020).

3. Villadsen SF, Mortensen LH, Andersen AMMN. Care during pregnancy and childbirth for migrant women: how do we advance? Development of intervention studies: the case of the MAMAACT intervention in Denmark. Best Pract Res Clin Obstet Gynaecol. 2016;32:100-12. doi:10.1016/j.bpobgyn.2015.08.013

4. Fair F, Raben L, Watson H, Vivilaki V, van den Muijsenbergh M, Soltani H, et al. Migrant women's experiences of pregnancy, childbirth and maternity care in European countries: a systematic review. PLoS ONE. 2020;15(2): e0228378. doi:10.1371/journal. pone.0228378 
5. Barkensjö M, Greenbrook JT, Rosenlundh J, Ascher H, Elden H. The need for trust and safety inducing encounters: a qualitative exploration of women's experiences of seeking perinatal care when living as undocumented migrants in Sweden. BMC Pregnancy Childbirth. 2018;18(1):1-17. doi:10.1186/s12884-018-1851-9

6. Brown-Bowers A, McShane K, Wilson-Mitchell K, Gurevich M. Postpartum depression in refugee and asylum-seeking women in Canada: a critical health psychology perspective. Health. 2015;19(3):318-35. doi:10.1177/1363459314554315

7. Stewart D, Gagnon A, Saucier J, Wahoush O, Dougherty G. Postpartum depression symptoms in newcomers. Can J Psychiatr. 2008;53(2):121-4. doi:10.1177/070674370805300208

8. Ahmed A, Bowen A, Feng CX. Maternal depression in Syrian refugee women recently moved to Canada: a preliminary study. BMC Pregnancy Childbirth. 2017;17(1):1-11. doi:10.1186/s12884-017-1433-2

9. Gieles NC, Tankink JB, van Midde M, Düker J, van der Lans P, Wessels CM, et al. Maternal and perinatal outcomes of asylum seekers and undocumented migrants in Europe: a systematic review. Eur J Public Health. 2019; 29(4):714-23. doi:10.1093/eurpub/ ckzO42

10. Kulu H, Hannemann T, Pailhé A, Neels K, Krapf S, González-Ferrer A, Andersson G. Fertility by birth order among the descendants of immigrants in selected European countries. Population Develop Rev. 2017;43(1):31-60.

11. Turkey Demographic and Health Survey 2018-Syrian Migrant Sample. Hacettepe University Institute of Population Studies; 2019. (http://www.hips.hacettepe.edu.tr/tnsa2018/rapor/2018_TDHS_SR.pdf, accessed 04 April 2021).

12. Turkey health statistics yearbook 2019 bulletin. Ankara: Ministry of Health; 2020. (https://dosyamerkez.saglik.gov.tr/ Eklenti/39024,haber-bulteni-2019pdf.pdf?o, accessed 04 April 2021).

13. Turkay Ü, Aydın Ü, Salıcı M, Çalışkan E, Terzi H, Astepe BS, et al. Comparison of pregnant Turkish women and Syrian refugees: Does living as a refugee have an unfavorable effect on pregnancy outcomes? Int J Gynecol Obstet. 2020;149(2):160-5. doi:10.1002/ijgo.13117

14. Korukcu O, Aydın R, Conway J, Kukulu K. Motherhood in the shade of migration: A qualitative study of the experience of Syrian refugee mothers living in Turkey. Nurs Health Sci. 2018;20(1):46-53. doi:10.1111/nhs.12379

15. Aktaş S, Aydın R. The analysis of negative birth experiences of mothers: a qualitative study. J Repro Infant Psychol. 2019;37(2):176-92. doi:10.1080/02646838.2018.1540863

16. Erenel H, Mathyk BA, Sal V, Ayhan I, Karatas S, Bebek AK. Clinical characteristics and pregnancy outcomes of Syrian refugees: a case-control study in a tertiary care hospital in Istanbul, Turkey. Arch Gynecol Obstet. 2017; 295(1): 45-50. doi:10.1007/s00404016-4188-5

17. Ozel S, Yaman S, Kansu-Celik H, Hancerliogullari N, Balci N, Engin-Ustun Y. Obstetric outcomes among Syrian refugees: A comparative study at a tertiary care maternity hospital in Turkey. Rev Bras Ginecol Obstet. 2018;40(11):673-79. doi:10.1055/s-0038-1673427

18. Crowther S, Lau A. Migrant Polish women overcoming communication challenges in Scottish maternity services: a qualitative descriptive study. Midwifery. 2019;72:30-8. doi:10.1016/j.midw.2019.02.004

19. Chu MS, Park M, Kim JA. First childbirth experience of international marriage migrant women in South Korea. Women Birth, 2017;30(4):e198-206. doi:10.1016/j.wombi.2017.01.001

20. Phillimore J. (2016). Migrant maternity in an era of superdiversity: new migrants' access to, and experience of, antenatal care in the West Midlands, UK. Soc Sci Med. 2016;148:152-9. doi:10.1016/j.socscimed.2015.11.030

21. Arousell J, Carlbom A. Culture and religious beliefs in relation to reproductive health. Best Pract Res Clin Obstet Gynaecol. 2016;32, 77-87. doi:10.1016/j.bpobgyn.2015.08.011

22. Refugees and asylum seekers in Turkey. Istanbul: UNHCR Turkey; 2020 (https://www.unhcr.org/tr/en/refugees-and-asylum-seekers-in-turkey, accessed 22 December 2020).

23. Geçici koruma [Temporary protection]. Ankara: Ministry of Interior, The Directorate General of Migration Management; 2020 (https://en.goc.gov.tr/temporary-protection27, accessed 22 December 2020)

24. Giorgi A. The descriptive phenomenological method in psychology: a modified Husserlian approach. Pittsburgh: Duquesne University Press; 2009.

25. Creswell JW, Poth CN. Qualitative inquiry and research design: choosing among five approaches. Thousand Oaks: Sage Publications; 2017.

26. van Manen M. Researching lived experience: human science for an action sensitive pedagogy, 2nd ed. Abingdon: Routledge; 1997.

27. Zapata-Barrero R, Yalaz E. Qualitative research in European migration studies. Springer; 2018.

28. Bollini P, Pampallona S, Wanner P, Kupelnick B. Pregnancy outcome of migrant women and integration policy: A systematic review of the international literature. Soc Sci Med. 2009;68(3):452-61. doi:10.1016/j.socscimed.2008.10.018

29. Pedersen GS, Grøntved A, Mortensen LH, Andersen A-MN, Rich-Edwards J. Maternal mortality among migrants in western Europe: a meta-analysis. Matern Child Health J. 2014;18(7):1628-38. doi:10.1007/s10995-013-1403-x

30. Migrant integration policy index (MIPEX). Barcelona: Barcelona Centre for International Affairs; 2015 (http://www.mipex.eu/, accessed 15 December 2020). 
31. Suphanchaimat R, Kantamaturapoj K, Putthasri W, Prakongsai P. Challenges in the provision of healthcare services for migrants: a systematic review through providers' lens BMC Health Serv Res. 2015;15(1):390. doi:10.1186/s12913-015-1065-Z

32. Benza S, Liamputtong P. Pregnancy, childbirth and motherhood: a meta-synthesis of the lived experiences of immigrant women. Midwifery. 2014;30(6):575-84. doi:10.1016/j.midw.2014.03.005

33. Phillimore J. Migrant maternity in an era of superdiversity: new migrants' access to, and experience of, antenatal care in the West Midlands, UK. Soc Sci Med. 2016;148:152-9. doi:10.1016/j.socscimed.2015.11.030

34. Orgel F, Merve AY. Antenatal classes for pregnant Syrian women on maternal health outcomes. Int Rev Migration Refugee Studies. 2020;1(1):12-22.

35. Sandall J, Soltani H, Gates S, Shennan A, Devane D. Midwife-led conti- nuity models versus other models of care for childbearing women. Cochrane Database Syst Rev. 2016;4:CD004667. doi:10.1002/14651858.CD004667.pub5

36. Alzghoul MM, Møller H, Wakewich P, Dowsley M. Perinatal care experiences of Muslim women in Northwestern Ontario, Canada: A qualitative study. Women Birth. 2021;34(2):e162-9. doi:10.1016/j.wombi.2020.02.021 